\title{
P-loop mutations and novel therapeutic approaches for imatinib failures in chronic myeloid leukemia Shundong Cang and Delong Liu*
}

\author{
Address: Division of Hematology/Oncology, New York Medical College, Valhalla, NY 10595, USA \\ Email: Shundong Cang - cangshundong@163.com; Delong Liu* - delong_liu@nymc.edu \\ * Corresponding author
}

Published: I October 2008

Journal of Hematology \& Oncology 2008, I:I5 doi:I0.1 I86/I756-8722-I-I5

This article is available from: http://www.jhoonline.org/content/l/I/l5

(C) 2008 Cang and Liu; licensee BioMed Central Ltd.

This is an Open Access article distributed under the terms of the Creative Commons Attribution License (http://creativecommons.org/licenses/by/2.0), which permits unrestricted use, distribution, and reproduction in any medium, provided the original work is properly cited.
Received: 8 July 2008

Accepted: I October 2008

\begin{abstract}
Imatinib was the first BCR-ABL-targeted agent approved for the treatment of patients with chronic myeloid leukemia (CML) and confers significant benefit for most patients; however, a substantial number of patients are either initially refractory or develop resistance. Point mutations within the $A B L$ kinase domain of the $B C R-A B L$ fusion protein are a major underlying cause of resistance. Of the known imatinib-resistant mutations, the most frequently occurring involve the ATP-binding loop (P-loop). In vitro evidence has suggested that these mutations are more oncogenic with respect to other mutations and wild type BCR-ABL. Dasatinib and nilotinib have been approved for secondline treatment of patients with CML who demonstrate resistance (or intolerance) to imatinib. Both agents have marked activity in patients resistant to imatinib; however, they have differential activity against certain mutations, including those of the P-loop. Data from clinical trials suggest that dasatinib may be more effective vs. nilotinib for treating patients harboring P-loop mutations. Other mutations that are differentially sensitive to the second-line tyrosine kinase inhibitors (TKIs) include $\mathrm{F} 3 \mathrm{I} / \mathrm{L}$ and $\mathrm{F} 359 \mathrm{I} / \mathrm{V}$, which are more sensitive to nilotinib and dasatinib, respectively. P-loop status in patients with CML and the potency of TKIs against P-loop mutations are key determinants for prognosis and response to treatment. This communication reviews the clinical importance of P-loop mutations and the efficacy of the currently available TKIs against them.
\end{abstract}

\section{Background}

Chronic myeloid leukemia (CML) accounts for approximately $20 \%$ of all adult leukemias in the United States [1]. Progression of CML is generally described as a three-phase process, beginning in a mostly asymptomatic chronic phase $(\mathrm{CP})$, progressing to an intermediate accelerated phase (AP) and followed by a usually terminal blast phase (BP) [1]. Left untreated, CML usually progresses from CP to BP over a period of 3 to 5 years [1].

CML is characterized by the Philadelphia chromosome, which results from a genetic translocation between chro- mosomes 9 and $22[2,3]$. This translocation results in fusion of the BCR and ABL genes, which code for a constitutively active BCR-ABL tyrosine kinase $[4,5]$. The activity of this BCR-ABL tyrosine kinase, including its anti-apoptotic effects, underlies the pathophysiologic basis of $\mathrm{CML}$ [6-8].

Modern treatment of CML relies upon tyrosine kinase inhibitors (TKIs) directed against BCR-ABL. Imatinib (Gleevec $^{\circledast}$, Novartis Pharmaceuticals Corporation, East Hanover, NJ, USA) was the first TKI approved for the treatment of $\mathrm{CML}$ and is the current first-line treatment. 
Approval of this agent was based on data from the International Randomized Study of Interferon and STI571 (IRIS) [9]. While most patients benefit from imatinib treatment, a substantial number either are initially refractory (primary resistance) or develop resistance during the course of treatment (acquired resistance). As a result of primary resistance to imatinib, $24 \%$ of patients in IRIS failed to achieve a complete cytogenetic response (CCyR) after 18 months [9]. Additionally, secondary resistance manifested as progression to advanced phases in $7 \%$ of patients and as relapsed disease in approximately $17 \%$ of patients [10].

Several underlying mechanisms of imatinib resistance have been identified. One major cause is the presence of point mutations within the ABL kinase domain of BCRABL. Such mutations inhibit the ability of imatinib to bind to BCR-ABL by corrupting the binding sites or preventing the kinase domain from assuming the inactive conformation required for imatinib binding [11]. Point mutations develop in approximately $35 \%$ to $70 \%$ of patients displaying resistance to imatinib, either spontaneously or through the evolutionary pressure of imatinib $[12,13]$.

More than 40 distinct resistance-conferring mutations have been detected; the majority fall within four regions of the kinase domain: the ATP-binding loop (P-loop) of the ABL kinase domain, the contact site, the SH2 binding site (activation loop), and the catalytic domain [14]. Approximately $85 \%$ of all imatinib-resistant mutations are associated with amino acid substitutions at just seven residues (P-loop: M244V, G250E, Y253F/H and E255K/V; contact site: T315I; and catalytic domain: M351T and F359V) [15]. The most frequently mutated region of BCR$\mathrm{ABL}$ is the P-loop, accounting for $36 \%$ to $48 \%$ of all mutations $[12,13]$.

The importance of P-loop mutations is further underlined by in vitro evidence suggesting that these mutations are more oncogenic with respect to unmutated BCR-ABL as well as other mutated variants [16]. In various biological assays, P-loop mutants Y253F and E255K exhibited an increased transformation potency relative to unmutated BCR-ABL. Overall, the relative transformation potencies of various mutations were found to be as follows: Y253F $>$ E255K > native BCR-ABL $\geq$ T315I > H396P > M351T. Transformation potency also correlated with intrinsic BCR-ABL kinase activity in this study.

Two agents are currently approved for second-line treatment of patients with CML who demonstrate resistance (or intolerance) to imatinib: dasatinib and nilotinib $[17,18]$. While both agents have marked activity in patients resistant to imatinib, they are differentially effica- cious against certain mutations, including those of the Ploop. Data from clinical trials suggest that dasatinib may be more effective than nilotinib in treating patients harboring P-loop mutations. This communication reviews the clinical importance of P-loop mutations and the efficacy of the currently available TKIs against them.

\section{P-loop mutations and the response to imatinib}

The mutations conferring resistance to imatinib have been well characterized [11]. The mutation analysis have been done using denaturing high-performance liquid chromatography and direct sequencing [15]. In the GIMEMA study, mutations were found in $43 \%$ of evaluable patients (127 of 297 patients). Among them, mutations were found in $27 \%$ with chronic phase patients, $52 \%$ of AP patients, and 75\% of myeloid BC, and $83 \%$ lymphoid BC/ $\mathrm{Ph}+\mathrm{ALL}$ [15]. The frequency of p-loop mutations clearly increases in accelerated phase and blast crisis as well as with disease duration $[11,15]$. Therefore patients with CML in these phases tend to develop imatinib-resistant mutations. Selection of resistant clones during therapy and clonal cytogenetic evolution with longer duration may be responsible for the development and expansion of the resistant clones with the mutations. These mechanisms argue against high-sensitivity mutation screening of all CML patients before therapy. It is prudent to do mutation analysis for patients who failed imatinib or have advanced CML.

As mentioned previously, the most widely studied and clinically dominant mechanisms of imatinib resistance involve acquired point mutations within the kinase domain of BCR-ABL. BCR-ABL mutants can be grouped based on imatinib sensitivity: sensitive $\left(\mathrm{IC}_{50} \leq 1000 \mathrm{nM}\right)$; intermediately sensitive $\left(\mathrm{IC}_{50} \leq 3000 \mathrm{nM}\right.$; ie, $\mathrm{M} 244 \mathrm{~V}$, G250E, Q252H, F317L and E355G); and insensitive ( IC $_{50}$ > $3000 \mathrm{nM}$; ie, Y253F/H, E255K/V and T315I). The various mutations occur at different frequencies and confer different levels of imatinib resistance (Fig. 1) [19].

The sensitivity of imatinib to many of these point mutations has been studied in vitro (Table 1). BCR-ABL mutated at the P-loop is 70-fold to 100-fold less sensitive to imatinib compared with native BCR-ABL. The presence of these mutations also has been associated with poor prognosis for patients receiving imatinib. Indeed, before the availability of second-line TKIs, patients with P-loop mutations treated with imatinib alone experienced reduced response and survival rates $[12,13,20]$. For example, Brandford et al. found that in patients with CP and AP CML, P-loop mutations were associated with death in 12 of 13 patients (92\%; median survival of 4.5 months) vs. 3 of 14 patients with mutations outside of the P-loop (21\%; median survival of 11 months) [12]. Similarly, Soverini et al. found that among CP patients with P-loop mutations, 


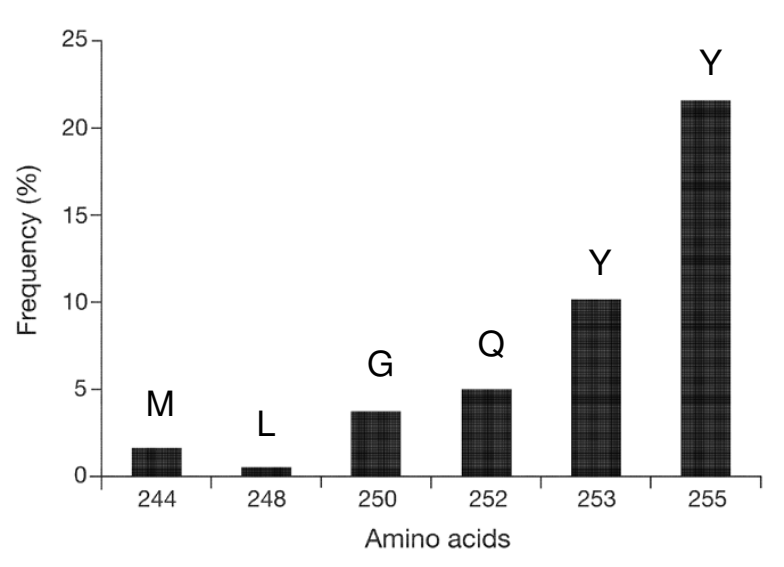

Figure I

Frequency of BCR-ABL P-loop mutations detected in I 77 clinical specimens. The positions of the P-loop amino acid residues were indicated. M-methionine; L-leucine; G-glycine; Q-glutamine; Y-tyrosine. (adapted from ref. [19]).

8 of 9 patients experienced disease progression to AP or BC after a median of 9 months from mutation detection and 12 months from the onset of imatinib [20]. Only 3 of 9 patients with mutations outside of the P-loop experienced disease progression to AP or BC. Deaths also were reported more frequently with P-loop mutations ( 6 of 9 patients compared with 1 of 9 patients). Similarly, Nicolini et al. observed that among 89 patients with CML (64\% CP) after a median follow-up of 39.2 months since imatinib initiation, overall survival was significantly worse for those with P-loop mutations (28.3 months) compared with other mutations (not reached) [21]. Furthermore, a recent study found that P-loop mutations were detectable 2.8 months before the development of resistance in patients taking imatinib compared with 6.3 months for T315I mutations, 10.8 months for M351T mutations, 2.9 months for A-loop mutations and 8.7 months for other mutations [22]. Additionally, of the 7 patients with mutations that were not detectable before relapse, $6(86 \%)$ had P-loop mutations. Taken together, this information highlights the increased rate of progression associated with Ploop mutations. Because the appearance of such mutations seems to indicate impending relapse and resistance to imatinib, earlier detection may provide clinical benefit for patients by prompting earlier reconsideration of therapeutic interventions [22].

In contrast, other studies in which patients were permitted to switch to second-line treatment showed no significant prognostic differences between patients carrying P-loop mutations vs. those with other mutations within BCR-ABL $[13,23]$. This result may be due to the availability of newer TKI therapies with greater activity against mutations of the P-loop for imatinib-resistant patients (Table 2). Alternatively, it is possible that the results of this study were influenced by differences in the specific P-loop mutations harbored by patients included in each study and/or differences in definition of the P-loop mutations may have contributed to different outcomes. With regard to the latter, Jabbour et al. defined P-loop mutations as those at residues 244 through 255 [13], while others included only mutations at residues 250 through 255 [12,20] or 248 through 255 [21].

As with all BCR-ABL mutants, P-loop mutations are detected more frequently in late-stage disease. Interestingly, advanced CML is an independent factor associated with their development $[12,13,15]$. When Soverini et al. examined the frequency and distribution of mutations according to disease phase at the time of diagnosis, they found that $52 \%$ of patients with AP CML and $75 \%$ of those with BP CML had mutations, compared with only $27 \%$ of patients in CP [15]. They also noticed a preferential association of P-loop and T315I mutations with advanced phase disease. This is not surprising, as support-

Table I: Sensitivity of Bcr-Abl kinase domain P-loop mutants to imatinib, nilotinib and dasatinib

\begin{tabular}{|c|c|c|c|c|}
\hline & & \multicolumn{3}{|c|}{$\mathrm{Ba} / \mathrm{F} 3$ cellular proliferation $\mathrm{IC}_{50}$ value } \\
\hline & & Imatinib (nM) & Nilotinib (nM) & Dasatinib (nM) \\
\hline M244V & P-loop & 2000 & 38 & 1.3 \\
\hline G250E & P-loop & 1350 & 48 & 1.8 \\
\hline Q252H & P-loop & 1325 & 70 & 3.4 \\
\hline Y253F & P-loop & 3475 & 125 & 1.4 \\
\hline Y253H & P-loop & $>6400$ & 450 & 1.3 \\
\hline E255K & P-loop & $>5000$ & 200 & 5.6 \\
\hline E255V & P-loop & $>6400$ & 430 & 11 \\
\hline
\end{tabular}

Imatinib: sensitive $(\leq 1000 \mathrm{nM})$, intermediate $(\leq 3000 \mathrm{nM})$, insensitive (> $3000 \mathrm{nM})$. Nilotinib: sensitive $(\leq 150 \mathrm{nM})$, intermediate $(=150 \mathrm{nM}$ to 450 $\mathrm{nM})$, insensitive (> $2000 \mathrm{nM})$. Dasatinib: sensitive $(\leq 5 \mathrm{nM})$, intermediate $(\leq 5 \mathrm{nM}$ to II nM), insensitive (> II nM). (adapted from Ref. I I).

Sensitive

Intermediate sensitivity

Insensitive 
Table 2: Efficacy of dasatinib and nilotinib in patients with CP CML harboring specific mutations

\begin{tabular}{lcc}
\hline & \multicolumn{2}{c}{ CCyR rates, $\mathrm{n} / \mathrm{N}(\%)$} \\
\cline { 2 - 3 } & Dasatinib & Nilotinib \\
\hline Any mutation & $158 / 369(43)$ & $18 / 77(23)$ \\
P-loop mutations & $61 / 141(43)$ & $\mathrm{NR}$ \\
L248V & $\mathrm{NR}$ & $0 / 2(0)$ \\
G250E & $19 / 51(37)$ & $1 / 4(25)$ \\
Y253F/H & $12 / 23(52)$ & $0 / 8(0)$ \\
E255K/N & $8 / 24(33)$ & $0 / 6(0)$ \\
T3I5I & $0 / 20(0)$ & $0 / 4(0)$ \\
F3I7L & $1 / 14(7)$ & $N R * \dagger$ \\
F359C/V & $14 / 27(52)$ & $0 / 10(0)^{*}$ \\
\hline
\end{tabular}

Dasatinib data are based on I,093 patients with CP CML enrolled in clinical trials with dasatinib [36]. Nilotinib data are based on 280 patients with CP CML enrolled in a phase 2 clinical trial with nilotinib [42].

*(Adapted from Ref. [45]).

tConsidered a nilotinib-sensitive mutation ( 18 of 45 patients harboring nilotinib-sensitive mutations achieved CCyRs) [45]. CP: chronic phase. CML: chronic myeloid leukemia. CCyR: complete cytogenetic response. NR: not reported.

ing pre-clinical evidence has shown the increased oncogenic potential of P-loop mutations [16].

\section{Dasatinib}

Dasatinib is a potent, orally active, dual BCR-ABL/Srcfamily kinase inhibitor [24]. Initial approval of dasatinib was based on data from the START (SRC/ABL Tyrosine kinase inhibition Activity: Research Trials of dasatinib) program, a series of multicenter, open-label phase 2 clinical trials in imatinib-resistant or -intolerant patients with CML or Philadelphia chromosome-positive acute lymphoblastic leukemia (Ph+ ALL). In the START-C trial, dasatinib was evaluated in patients with CP CML who were resistant or intolerant of imatinib [25]. A recent update to this trial showed that following 24 months of treatment, dasatinib $70 \mathrm{mg}$ twice daily was associated with a high rate of durable cytogenetic responses in patients with CP CML who were resistant or intolerant to imatinib (Table 3) [26]. After 24 months of treatment, the major cytogenetic response (MCyR) rate was $62 \%$ and responses were durable with $88 \%$ of patients maintaining their response. The CCyR rate was 53\% and the major molecular response was $47 \%$. Additionally, at 24 months, progression-free survival was $80 \%$ (75\% in imatinibresistant and $94 \%$ in imatinib-intolerant patients) and overall survival was $94 \%$ (92\% in imatinib-resistant and $100 \%$ in imatinib-intolerant patients) [26]. Marked activity also was noted in advanced disease $[27,28]$.

Dasatinib was initially approved at a dosage of $70 \mathrm{mg}$ twice daily (with or without food) for all stages of CML. The label has recently been updated such that $100 \mathrm{mg}$ once daily is now the recommended regimen in CP CML [17]. This update was based on an open-label, dose-optimization study in which patients were randomized (1:1:1:1) to receive one of four dasatinib regimens: 100 mg once daily, $50 \mathrm{mg}$ twice daily, $140 \mathrm{mg}$ once daily or 70 mg twice daily [29]. The 100-mg, once-daily dosage demonstrated equivalent efficacy compared with the previously recommended 70-mg twice-daily dosage and was associated with fewer grade $3 / 4$ adverse events (AEs; 30\% vs. $48 \%$, respectively) [29]. Most significantly, the 100-mg dose was associated with lower rates of pleural effusions (7\% vs. $16 \%$ ) and grade $3 / 4$ thrombocytopenia (22\% vs. $37 \%$ ). Most other AEs were mild to moderate (grades 1/2) in severity and tended to resolve either spontaneously or with supportive care. Additionally, fewer discontinuations and dose modifications occurred in the 100-mg once-daily arm compared with the 70-mg twice-daily arm. Following results of this trial, the recommended starting dose of dasatinib for imatinib-resistant or -intolerant patients with CP CML was changed to $100 \mathrm{mg}$ once daily [17]. The 70-mg twice-daily dosage remains the recommended starting dosage for patients with advanced phase disease (AP/BP CML or Ph+ ALL).

The marked activity of dasatinib in patients resistant to imatinib can be understood by noting its mechanism of action. Due to structural differences from imatinib and nilotinib, dasatinib is active against most of the imatinibrelated mutations that lead to resistance. Dasatinib binds multiple conformations of BCR-ABL [30], unlike imatinib and nilotinib [31,32]. The ability to bind both active and inactive conformations of BCR-ABL may explain its potent activity against most of the known imatinib-resist-

Table 3: Clinical responses to dasatinib and nilotinib in CML treatment

\begin{tabular}{lcccccccc}
\hline Patients & \multicolumn{2}{c}{ McyR(\%) } & & CCyR (\%) & & PFS (\%) & OS (\%) \\
\hline & DAS & NIL & DAS & NIL & DAS & NIL & DAS & NIL \\
\hline Imatinib-resistant & 55 & 48 & NR & 30 & 75 & NR & 92 & NR \\
Imatinib-intolerant & 78 & 47 & 78 & 35 & 94 & NR & 100 & NR \\
All patients & 62 & 48 & 53 & 31 & 80 & NR & 94 & NR \\
\hline
\end{tabular}

MCyR: major cytogenetic remission; CCyR: complete cytogenetic remission; PFS: progression free survival; OS: overall survival; DAS: Dasatinib; NIL: nilotinib; NR: not reported [26,42]. 
ant kinase domain mutations, with the exception of T315I [33]. Dasatinib is also more potent than imatinib, with 325 -fold greater in vitro activity against unmutated BCRABL [31]. The increased potency of dasatinib, combined with its ability to bind multiple conformation of BCR$\mathrm{ABL}$, produces significant efficacy in patients with $\mathrm{CML}$ and $\mathrm{Ph}+\mathrm{ALL}$. The sensitivity of BCR-ABL mutants to dasatinib can be classified as sensitive $\left(\mathrm{IC}_{50} \leq 5 \mathrm{nM}\right)$, intermediately sensitive $\left(\mathrm{IC}_{50}=5\right.$ to $11 \mathrm{nM} ; \mathrm{ie}, \mathrm{E} 255 \mathrm{~K} / \mathrm{V}$ and $\mathrm{F} 317 \mathrm{~L})$ and insensitive $\left(\mathrm{IC}_{50}>11 \mathrm{nM}\right.$; ie, T315I) (Table 1). T315I, a contact point mutation, is insensitive to all currently approved BCR-ABL inhibitors [30,31,33-35]. Ploop mutated BCR-ABL is generally sensitive or intermediately sensitive to dasatinib, with $\mathrm{IC}_{50}$ values falling in the range of 1 to $11 \mathrm{nM}$ [11].

Responses to dasatinib in patients with CP CML $(n=961)$ have been assessed by baseline mutational status [36]. Equivalent CCyR rates were noted in imatinib-resistant patients with P-loop mutations (61 of $141 ; 43 \%$ ) and all other patients, except those with T315I and F317L mutations ( 140 of $336 ; 42 \%$ ). In this study, no patients ( 0 of 20) with T315I mutations and only 7\% (1 of 14) of patients with F317L mutations achieved CCyRs. These mutations are therefore insensitive to dasatinib. With regard to individual P-loop mutations, CCyR rates were similar to or above those of patients without mutated BCR-ABL: G250E, 37\% (19 of 51); Y253F/H, 52\% (12 of 23); and E255K/V, 33\% (8 of 24) (Table 2). Patients with CP CML enrolled in the phase 2 START-C trial were also evaluated by baseline mutational status [37]. The results from this trial were similar to those above. One resistant patient with a Q252H mutation was observed; however, further data are needed to determine the sensitivity of this mutation to dasatinib. Moreover, as this mutation is more sensitive to dasatinib than $\mathrm{E} 255 \mathrm{~K}$ in vitro, it is probable that patients with $\mathrm{Q} 252 \mathrm{H}$ mutations would respond at least as well as those with E255K/V. Based on the available data, P-loop mutations are not likely to pose a significant barrier to treatment with dasatinib.

Mutations have been shown to develop with dasatinib exposure. In an in vitro mutagenesis study, nine dasatinibresistant mutations involving six residues were found. However, only F317V and T315I were isolated at intermediate drug concentrations, and T315I was the only mutation to be detected at maximal achievable plasma concentrations [38]. In clinical studies, T315A/I, F317I/L and V299L are the most frequent mutations associated with dasatinib resistance [37,39-41]. In the phase 2 START-C trial of patients with CP disease, new mutations were detected in $11 \%$ of patients (22 of 201), including $6 \%$ (13 of 201) with T315A/I, F317L or V299L ( 4 of 201, 7 of 201 and 2 of 201 patients, respectively) [38]. Importantly, these mutations are uncommon at baseline.
Among all baseline mutations, F317L and T315I mutations have been detected with frequencies of approximately 5\% each [37]. T315A and V299L mutations were not detected.

\section{Nilotinib}

Nilotinib is an analog of imatinib with 10 -fold to 50 -fold greater potency against unmutated BCR-ABL than its parent compound [35]. The approval of nilotinib was based on the release of data from a single open-label phase 2 study of patients with CP or AP CML who were resistant or intolerant to prior imatinib therapy $[42,43]$.

In the phase 2 study, following at least 6 months of treatment, rates of MCyR and CCyR rates were $48 \%$ and $31 \%$, respectively [42]. Among patients who achieved a MCyR, $96 \%$ continued treatment without progression or death for at least 6 months (Table 3). In total, $11 \%$ of patients discontinued treatment because of disease progression in this study.

Most AEs were mild to moderate in severity and were generally able to be managed with dose reduction or interruption and appropriate supportive care. The most frequent grade 3/4 AEs in patients with CP CML were neutropenia (29\%), thrombocytopenia (29\%), asymptomatic serum lipase elevation (14\%) and bilirubin elevation (9\%) [42]. In total, $15 \%$ of patients discontinued treatment as a result of AEs [43]. Cross-intolerance was defined as the reoccurrence of a grade $3 / 4 \mathrm{AE}$ during nilotinib treatment that caused the discontinuation of imatinib. Cross-intolerance to nilotinib occurred in $49 \%$ of patients with hematologic intolerance to imatinib, mostly due to the reoccurrence of thrombocytopenia [44]. In clinical trials, nilotinib treatment has been associated with prolongation of the QTc interval, and sudden deaths have occurred, which are likely related to ventricular repolarization abnormalities. The prescribing information for nilotinib carries a black box warning regarding the risk of these events [18].

Nilotinib has clinical activity in patients with all BCR-ABL mutations associated with imatinib resistance except T315I [42]. However, accumulated evidence suggests that nilotinib also possesses relative insensitivities to certain BCR-ABL mutations. Ten nilotinib-insensitive BCR-ABL mutations have been identified in vitro [38]. In contrast to dasatinib, P-loop mutations are among the most resistant, with $\mathrm{IC}_{50} \mathrm{~s}$ ranging from $38 \mathrm{nM}$ to $450 \mathrm{nM}$ [11]. In a mutagenesis study, the P-loop mutations $\mathrm{Y} 253 \mathrm{H}$ and E255V were persistent at intermediate drug concentrations and, as with dasatinib, only T315I was isolated at maximal achievable plasma concentrations [38]. 
In the key phase 2 study, no CCyRs were observed in patients harboring L248V, Y253H or E255K/V mutations [42]. Additionally, patients with G250E mutations had a CCyR rate of $25 \%$, which is lower than that in the overall population (30\%). In another study in patients with CP CML receiving nilotinib, no patients with $\mathrm{F} 359 \mathrm{C} / \mathrm{V}$ mutations experienced a CCyR [45] (Table 2). Y253H and E255K/V mutations are also among those that develop most frequently during nilotinib therapy and have been linked to disease progression [46]. Y253H, E255K/V and F359C mutations occurred in $8 \%$ of those assessed for baseline mutations (23\% of all mutations). These mutations were associated with disease progression in $50 \%$ of cases [45]. Among patients with AP CML, the same mutations were associated with disease progression in $64 \%$ [47]. Notably, the incidences of nilotinib-resistant mutations at baseline and at progression are higher than those for dasatinib-resistant mutations. The P-loop mutations E255K/V, Y253H and F359C/V accounted for 25\% (26 of 104) of all baseline mutations [45]. Furthermore, among 40 imatinib-resistant patients who developed mutations during nilotinib therapy, 22 (55\%) had newly detectible mutations of the P-loop (10 [25\%] with E255K/V; 7 [18\%] with G250E; and 5 [13\%] with Y253H).

\section{Future agents}

Because none of the currently available TKIs are effective against T315I mutations, there is a clear need to develop alternative options for patients with such mutations. Several agents are in clinical development, including novel TKIs and aurora kinase inhibitors.

Bosutinib (SKI-606) is a dual Src/Abl TKI with 200-fold greater potency than imatinib against BCR-ABL in biochemical assays [48]. Bosutinib is currently being evaluated in a phase 3 trial of patients with CP CML. Unfortunately, in vitro studies have shown that bosutinib is not active against T315I [49,50]. In a phase $1 / 2$ study, 48 patients with CP CML who were imatinib resistant or intolerant were treated with bosutinib $500 \mathrm{mg}$ daily [51]. Of evaluable patients, $84 \%$ (16 of 19) achieved a complete hematologic response (CHR), and MCyRs were achieved in $52 \%$ ( 11 of 21 ). The most common grade $3 / 4$ toxicities occurring in $\geq 5 \%$ of patients were thrombocytopenia (6\%) and rash (6\%). Diarrhea (69\%), nausea (44\%), vomiting (19\%), abdominal pain (13\%) and rash $(13 \%)$ were the most common grade $1 / 2$ toxicities. Given that bosutinib has minimal activity against c-Kit and platelet-derived growth factor receptors, it may be associated with a lower incidence of AEs related to the inhibition of these targets (eg, edema, muscle cramps, skin rash, pigmentation, endocrine abnormalities, low-grade inhibition of normal hemopoiesis) than other TKIs $[49,50]$.
In the phase $1 / 2$ trials of bosutinib, 13 imatinib-resistant mutations were identified in 32 patients. Preliminary results showed CHR in 12 of 14 patients with non-P-loop mutations and 3 of 3 patients with P-loop mutations. MCyR was demonstrated in 5 of 11 patients with non-Ploop mutations and 1 of 1 patient with P-loop mutations [51].

Other agents in development that may prove useful against T315I mutations include aurora kinase inhibitors. One such aurora kinase inhibitor, MK-0457, was the first agent to demonstrate clinical activity against the T315I phenotype [52]. In the study of 14 currently evaluable patients with CML, 11 had an objective (hematologic, cytogenetic and/or molecular) response, including all 9 patients with the T315I mutation [53]. Recently, however, clinical trials of MK-0457 were suspended due to cardiotoxicity concerns. Trials of other aurora kinase inhibitors, including PHA-739358 (phase 2), AP-24534 (phase 1) and XL-228 (phase 1), are ongoing. In early-stage clinical trials of PHA-739358, responses have been observed among patients with T315I mutations [54]. AP-24534 and XL-228 have demonstrated activity in cell culture and in mice bearing xenograft tumors expressing T315I BCR-ABL mutants $[55,56]$. A phase 1 open-label trial of XL-228 has been initiated in patients with $\mathrm{Ph}+$ leukemia, and clinical trials of patients with drug-resistant CML are planned for AP-24534.

\section{Conclusion}

P-loop mutations in the BCR-ABL gene account for nearly half of all mutations [12,13]. The mutations impart increased transformation potency with respect to other mutations and wild type BCR-ABL. Furthermore, Y253H and $\mathrm{E} 255 \mathrm{~K} / \mathrm{V}$ are commonly present at baseline before second-line treatment.

Dasatinib and nilotinib have differential activity against certain mutations, including those of the P-loop. Clinical resistance to dasatinib has been noted for T315I and F317L mutations but not for P-loop mutations. Additionally, P-loop mutations rarely emerge during dasatinib treatment. Y253H or E255K/V are commonly associated with clinical resistance to nilotinib and can develop during treatment. Nilotinib resistance is also associated with other mutations (ie, F359 and T315I).

Based on the currently available data, dasatinib may be a suitable second-line therapy for patients resistant to imatinib and who harbor P-loop or F359 mutations, while nilotinib may be an appropriate treatment option for patients with F317L mutations. Clearly, additional treatments are needed for patients harboring T315I. Currently, such patients should be considered for allogeneic stem cell transplantation or entry into a clinical trial. 


\section{List of abbreviations}

CML: chronic myeloid leukemia; CP: chronic phase; AP: accelerated phase; BP: blast phase; TKI: tyrosine kinase inhibitor; IRIS: International Randomized Study of Interferon and STI571; CCyR: complete cytogenetic response; START: SRC/ABL Tyrosine kinase inhibition Activity: Research Trials of dasatinib; Ph+ ALL: Philadelphia chromosome-positive acute lymphoblastic leukemia; MCyR: major cytogenetic response; AE: adverse event; CHR: complete hematologic response.

\section{Authors' contributions}

SC and DL involved in concept design, coordination, drafting and critically revising the manuscript.

\section{Acknowledgements}

Shundong Cang is a CAHON (CAHON.ORG) Research Scholar and a recipient of a fellowship grant from the International Scholar Exchange Foundation. This work was partly supported by New York Medical College Blood Diseases Fund. Writing and editorial support were provided by Erin Nagle and Josh Collis and funded by Bristol-Myers Squibb Company.

\section{References}

I. Sawyers CL: Chronic myeloid leukemia. N Engl J Med 1999, 340: $1330-1340$.

2. Nowell PC: A minute chromosome (Phl) in chronic granulocytic leukemia. Blut 1962, 8:65-66.

3. Rowley JD: Letter: a new consistent chromosomal abnormality in chronic myelogenous leukaemia identified by quinacrine fluorescence and Giemsa staining. Nature 1973, 243:290-293.

4. Daley GQ, Van Etten RA, Baltimore D: Induction of chronic myelogenous leukemia in mice by the P2IObcr/abl gene of the Philadelphia chromosome. Science 1990, 247:824-830.

5. Faderl S, Talpaz M, Estrov Z, O'Brien S, Kurzrock R, Kantarjian HM: The biology of chronic myeloid leukemia. N Engl J Med 1999, 341:164-I72.

6. Bartram CR, de Klein A, Hagemeijer A, van Agthoven T, Geurts vK, Bootsma D, Grosveld G, Ferguson-Smith MA, Davies T, Stone M, Heisterkamp N, Stephenson JR, Groffen J: Translocation of c-ab I oncogene correlates with the presence of a Philadelphia chromosome in chronic myelocytic leukaemia. Nature 1983, 306:277-280.

7. Groffen J, Stephenson JR, Heisterkamp N, de Klein A, Bartram CR, Grosveld G: Philadelphia chromosomal breakpoints are clustered within a limited region, bcr, on chromosome 22. Cell 1984, 36:93-99.

8. Lugo TG, Pendergast AM, Muller AJ, Witte ON: Tyrosine kinase activity and transformation potency of bcr-abl oncogene products. Science 1990, 247: 1079-1082.

9. O'Brien SG, Guilhot F, Larson RA, Gathmann I, Baccarani M, Cervantes F: Imatinib compared with interferon and low-dose cytarabine for newly diagnosed chronic-phase chronic myeloid leukemia. N Engl J Med 2003, 348:994-1004.

10. Druker BJ, Guilhot F, O'Brien SG, Gathmann I, Kantarjian H, Gattermann N, Deininger MW, Silver RT, Goldman JM, Stone RM, Cervantes F, Hochhaus A, Powell BL, Gabrilove JL, Rousselot P, Reiffers J, Cornelissen JJ, Hughes T, Agis H, Fischer T, Verhoef G, Shepherd J, Saglio G, Gratwohl A, Nielsen JL, Radich JP, Simonsson B, Taylor K, Baccarani M, So C, Letvak L, Larson RA, for the IRIS Investigators: Five-year follow-up of patients receiving imatinib for chronic myeloid leukemia. N Engl J Med 2006, 355:2408-24I7.

II. O'Hare T, Eide CA, Deininger MWN: Bcr-Abl kinase domain mutations, drug resistance, and the road to a cure for chronic myeloid leukemia. Blood 2007, I I 0:2242-2249.

12. Branford S, Rudzki Z, Walsh S, Parkinson I, Grigg A, Szer J, Taylor K, Herrmann R, Seymour JF, Arthur C, Joske D, Lynch K, Hughes T: Detection of BCR-ABL mutations in patients with CML treated with imatinib is virtually always accompanied by clin- ical resistance, and mutations in the ATP phosphate-binding loop (P-loop) are associated with a poor prognosis. Blood 2003, 102:276-283.

13. Jabbour E, Kantarjian H, Jones D, Talpaz M, Bekele N, O'Brien S, Zhou X, Luthra R, Garcia-Manero G, Giles F, Rios MB, Verstovsek S, Cortes $\mathrm{J}$ : Frequency and clinical significance of BCR-ABL mutations in patients with chronic myeloid leukemia treated with imatinib mesylate. Leukemia 2006, 20:1767-1773.

14. Hughes T, Deininger M, Hochhaus A, Branford S, Radich J, Kaeda J, Baccarani M, Cortes J, Cross NC, Druker BJ, Gabert J, Grimwade D, Hehlmann R, Kamel-Reid S, Lipton JH, Longtine J, Martinelli G, Saglio G, Soverini S, Stock W, Goldman JM: Monitoring CML patients responding to treatment with tyrosine kinase inhibitors: review and recommendations for harmonizing current methodology for detecting BCR-ABL transcripts and kinase domain mutations and for expressing results. Blood 2006, 108:28-37.

15. Soverini S, Colarossi S, Gnani A, Rosti G, Castagnetti F, Poerio A, lacobucci I, Amabile M, Abruzzese E, Orlandi E, Radaelli F, Ciccone F, Tiribelli M, di Lorenzo R, Caracciolo C, Izzo B, Pane F, Saglio G, Baccarani M, Martinelli G, GIMEMA Working Party on Chronic Myeloid Leukemia: Contribution of ABL kinase domain mutations to imatinib resistance in different subsets of Philadelphia-positive patients: by the GIMEMA Working Party on Chronic Myeloid Leukemia. Clin Cancer Res 2006, I 2:7374-7379.

16. Griswold IJ, MacPartlin M, Bumm T, Goss VL, O'Hare T, Lee KA, Corbin AS, Stoffregen EP, Smith C, Johnson K, Moseson EM, Wood LJ, Polakiewicz RD, Druker BJ, Deininger MW: Kinase domain mutants of Bcr-Abl exhibit altered transformation potency, kinase activity, and substrate utilization, irrespective of sensitivity to imatinib. Mol Cell Biol 2006, 26:6082-6093.

17. Sprycel [prescribing information]. New York, NY: BristolMyers Squibb Company; 2007.

18. Tasigna [prescribing information]. East Hanover, NJ: Novartis Pharmaceuticals Corporation; 2007.

19. Deininger $M$, Buchdunger $E$, Druker $B$ J: The development of imatinib as a therapeutic agent for chronic myeloid leukemia. Blood 2005, 105:2640-2653.

20. Soverini S, Martinelli G, Rosti G, Bassi S, Amabile M, Poerio A, Giannini B, Trabacchi E, Castagnetti F, Testoni N, Luatti S, de Vivo A, CilIoni D, Izzo B, Fava M, Abruzzese E, Alberti D, Pane F, Saglio G, Baccarani M: ABL mutations in late chronic phase chronic myeloid leukemia patients with up-front cytogenetic resistance to imatinib are associated with a greater likelihood of progression to blast crisis and shorter survival: a study by the GIMEMA Working Party on Chronic Myeloid Leukemia. J Clin Oncol 2005, 23:4100-4109.

21. Nicolini FE, Corm S, Lê QH, Sorel N, Hayette S, Bories D, Leguay T, Roy L, Giraudier S, Tulliez M, Facon T, Mahon FX, Cayuela JM, Rousselot P, Michallet M, Preudhomme C, Guilhot F, Roche-Lestienne C: Mutation status and clinical outcome of 89 imatinib mesylate-resistant chronic myelogenous leukemia patients: a retrospective analysis from the French intergroup of CML (Fi(phi)-LMC GROUP). Leukemia 2006, 20:1061-1066.

22. Ernst $T$, Erben $P$, Müller MC, Paschka $P$, Schenk T, Hoffmann J: Dynamics of BCR-ABL mutated clones prior to hematologic or cytogenetic resistance to imatinib. Haematologica 2008, 93:186-192.

23. Hochhaus A, Ernst T, Erben P, Mueller MC, Emig M, Kreil S, La Rosée P, Lahaye T, Schatz M, Ottman OG, Schnittger S, Berger U, Hehlmann $\mathrm{R}$ : Long term observation of CML patients after imatinib resistance associated with BCR-ABL mutations. Blood(ASH Annual Meeting Abstracts) 2005, 106:. Abstract 1086.

24. Lombardo LJ, Lee FY, Chen P, Norris D, Barrish JC, Behnia K, Castaneda S, Cornelius LA, Das J, Doweyko AM, Fairchild C, Hunt JT, Inigo I, Johnston K, Kamath A, Kan D, Klei H, Marathe P, Pang S, Peterson R, Pitt S, Schieven GL, Schmidt RJ, Tokarski J, Wen ML, Wityak J, Borzilleri RM: Discovery of N-(2-chloro-6-methyl-phenyl)-2-(6-(4-(2-hydroxyethyl)-piperazin-I-yl)-2-

methylpyrimidin-4-ylamino)thiazole-5-carboxamide (BMS354825), a dual SrclAbl kinase inhibitor with potent antitumor activity in preclinical assays. J Med Chem 2004, 47:6658-666।.

25. Hochhaus A, Kantarjian HM, Baccarani M, Lipton JH, Apperley JF, Druker B], Facon T, Goldberg SL, Cervantes F, Niederwieser D, Silver RT, Stone RM, Hughes TP, Muller MC, Ezzeddine R, Countouriotis 
AM, Shah NP: Dasatinib induces notable hematologic and cytogenetic responses in chronic-phase chronic myeloid leukemia after failure of imatinib therapy. Blood 2007, 109:2303-2309.

26. Cervantes F, Baccarani M, Lipton J, Matloub Y, Sinha S, Stone R, Mauro M: Dasatinib long-term efficacy in patients with chronic myeloid leukemia in chronic phase (CML-CP) with resistance or intolerance to imatinib: a 2-year update of the START-C Study. Haematologica (EHA Annual Meeting Abstracts) 2008, 93:372-372. Abstract 0934.

27. Cortes J, Rousselot P, Kim DW, Ritchie E, Hamerschlak N, Coutre S, Hochhaus A, Guilhot F, Saglio G, Apperley J, Ottmann O, Shah N, Erben P, Branford S, Agarwal P, Gollerkeri A, Baccarani M: Dasatinib induces complete hematologic and cytogenetic responses in patients with imatinib-resistant or -intolerant chronic myeloid leukemia in blast crisis. Blood 2007, 109:3207-3213.

28. Guilhot F, Apperley J, Kim DW, Bullorsky EO, Baccarani M, Roboz GJ, Amadori S, de Souza CA, Lipton JH, Hochhaus A, Heim D, Larson RA, Branford S, Muller MC, Agarwal P, Gollerkeri A, Talpaz M: Dasatinib induces significant hematologic and cytogenetic responses in patients with imatinib-resistant or -intolerant chronic myeloid leukemia in accelerated phase. Blood 2007, 109:4 I43-4I50.

29. Shah NP, Kantariian H, Kim DW, Réa D, Dorlhiac-Llacer PE, Milone J, Vela-Ojeda J, Silver RT, Khoury HJ, Charbonnier A, Khoroshko N, Paquette RL, Deininger M, Collins RH, Otero I, Hughes T, Bleickardt $\mathrm{E}$, Strauss L, Francis S, Hochhaus A: Intermittent target inhibition with dasatinib (100 mg once daily) preserves efficacy and improves tolerability in imatinib-resistant and -intolerant chronic-phase chronic myeloid leukemia. J Clin Oncol 2008, 26:3204-32/2

30. O'Hare T, Walters DK, Stoffregen EP, Jia T, Manley PW, Mestan J, Cowan-Jacob SW, Lee FY, Heinrich MC, Deininger MW, Druker B] In vitro activity of Bcr-Abl inhibitors AMNIO7 and BMS354825 against clinically relevant imatinib-resistant $A$ bl kinase domain mutants. Cancer Res 2005, 65:4500-4505.

31. Tokarski JS, Newitt JA, Chang CY, Cheng JD, Wittekind M, Kiefer SE, Kish K, Lee FY, Borzillerri R, Lombardo LJ, Xie D, Zhang Y, Klei HE: The structure of dasatinib (BMS-354825) bound to activated ABL kinase domain elucidates its inhibitory activity against imatinib-resistant ABL mutants. Cancer Res 2006, 66:5790-5797.

32. Mestan J, Weisberg E, Cowan-Jacob S, Fabbro D, Furet P, Fendrich G, Goutte G, Kempf D, Gangler M, Griffin DJ, Manley PW: AMN I 07: in vitro profile of a new inhibitor of the tyrosine kinase activity of Bcr-Abl. Blood (ASH Annual Meeting Abstracts) 2004, 104: Abstract 1978

33. Shah NP, Tran C, Lee FY, Chen P, Norris D, Sawyers CL: Overriding imatinib resistance with a novel ABL kinase inhibitor. Science 2004, 305:399-40I

34. La Rosée P, Corbin AS, Stoffregen EP, Deininger MW, Druker BJ: Activity of the Bcr-Abl kinase inhibitor PDI80970 against clinically relevant $\mathrm{Bcr}-\mathrm{Abl}$ isoforms that cause resistance to imatinib mesylate (Gleevec, STI57I). Cancer Res 2002, 62:7|49-7|53

35. Weisberg E, Manley PW, Breitenstein W, Brüggen J, Cowan-Jacob SW, Ray A, Huntly B, Fabbro D, Fendrich G, Hall-Meyers E, Kung AL, Mestan J, Daley GQ, Callahan L, Catley L, Cavazza C, Azam M, Neuberg D, Wright RD, Gilliland DG, Griffin JD: Characterization of AMN 107, a selective inhibitor of native and mutant Bcr-Abl. Cancer Cell 2005, 7:129-141.

36. Mueller MC, Branford S, Radich J, Shah N, Erben P, Ernst T: Efficacy of dasatinib in chronic phase chronic myelogenous leukemia patients after imatinib failure according to baseline BCRABL mutations. Haematologica (EHA Annual Meeting Abstracts) 2007, 92: I27-127. Abstract 0356

37. Mueller MC, Erben P, Ernst T, Giehl M, Schenk T, Hoffmann J, Lauber S, Kruth J, Hanfstein B, Bleickardt E, Nicaise C, Hehlmann R, Hochhaus $A$ : Molecular response according to type of preexisting BCR-ABL mutations after second line dasatinib therapy in chronic phase CML patients. Blood (ASH Annual Meeting Abstracts) 2007, II0:. Abstract 319.

38. Bradeen HA, Eide CA, O'Hare T, Johnson KJ, Willis SG, Lee FY, Druker BJ, Deininger MW: Comparison of imatinib mesylate, dasatinib (BMS-354825), and nilotinib (AMNI07) in an Nethyl-N-nitrosourea (ENU)-based mutagenesis screen: high efficacy of drug combinations. Blood 2006, 108:2332-2338.
39. Soverini S, Colarossi S, Gnani A, Castagnetti F, Rosti G, Bosi C, Paolini S, Rondoni M, Piccaluga PP, Palandri F, Giannoulia P, Marzocchi G, Luatti S, Testoni N, lacobucci I, Cilloni D, Saglio G, Baccarani M, Martinelli G: Resistance to dasatinib in Philadelphia-positive leukemia patients and the presence or the selection of mutations at residues 315 and 317 in the BCR-ABL kinase domain. Haematologica 2007, 92:40I-404.

40. Shah NP, Skaggs BJ, Branford S, Hughes TP, Nicoll JM, Paquette RL, Sawyers CL: Sequential ABL kinase inhibitor therapy selects for compound drug-resistant BCR-ABL mutations with altered oncogenic potency. J Clin Invest 2007, I I 7:2562-2569.

4I. Khorashad JS, Milojkovic D, Mehta P, Anand M, Ghorashian S, Reid AG, De Melo V, Babb A, de Lavallade H, Olavarria E, Marin D, Goldman JM, Apperley JF, Kaeda JS: In vivo kinetics of kinase domain mutations in CML patients treated with dasatinib after failing imatinib. Blood 2008, I I I:2378-238I.

42. Kantarjian HM, Giles F, Gattermann N, Bhalla K, Alimena G, Palandri F, Ossenkoppele GJ, Nicolini FE, O'Brien SG, Litzow M, Bhatia R, Cervantes F, Haque A, Shou Y, Resta DJ, Weitzman A, Hochhaus A, le Coutre P: Nilotinib (formerly AMNI07), a highly selective BCR-ABL tyrosine kinase inhibitor, is effective in patients with Philadelphia chromosome positive chronic myelogenous leukemia in chronic phase following imatinib resistance and intolerance. Blood 2007, I 1 0:3540-3546.

43. Kantarjian $\mathrm{H}$, Hochhaus A, Cortes J, Martinelli G, Bhalla KN, Giles FJ, Ossenkoppel G, Gattermann N, Haque A, Gallagher N, Baccarani M, le Coutre $\mathrm{P}$ : Nilotinib is highly active and safe in chronic phase chronic myelogenous leukemia (CML-CP) patients with imatinib-resistance or intolerance. Blood (ASH Annual Meeting Abstracts) 2007, I1 0:. Abstract 735

44. Cortes J, Jabbour E, Hochhaus A, le Coutre P, Baccarani M, Bhalla KN, Ossenkoppel G, Gattermann N, Haque A, Gallagher N, Giles F, Kantarjian HM: Nilotinib is associated with minimal cross intolerance to imatinib in patients with imatinib-intolerant Philadelphia-positive $(\mathrm{Ph}+)$ chronic myelogenous leukemia (CML) in either chronic phase (CP) or accelerated phase (AP). Blood (ASH Annual Meeting Abstracts) 2007, I l0:. Abstract 1040.

45. Hughes T, Saglio G, Martinelli G, Kim DW, Soverini S, Mueller M, Haque A, Gallagher N, Shou Y, Radich J, Branford S, Hochhaus A: Responses and disease progression in CML-CP patients treated with nilotinib after imatinib failure appear to be affected by the BCR-ABL mutation status and types. Blood (ASH Annual Meeting Abstracts) 2007, I I 0:. Abstract 320.

46. Branford S, Shou Y, Lawrence R, Rudzki Z, Hughes T: The P-loop mutations $\mathrm{Y} 253 \mathrm{H}$ and $E 255 \mathrm{~K} / \mathrm{V}$ may develop more frequently than $\mathrm{T} 3151$ during nilotinib therapy after imatinib failure and are associated with progression in patients with Ph-positive leukemias. Haematologica (EHA Annual Meeting Abstracts) 2007, 92:337-338. Abstract 0904.

47. Saglio G, Kim DW, Hochhaus A, Soverini S, Erben P, Branford S, Haque A, Gallagher N, Shou Y, Hughes T, Martinelli G, Radich J: Correlation of clinical response to nilotinib with $B C R-A B L$ mutation status in advanced phase chronic myelogenous leukemia (CML-AP) patients with imatinib-resistance or intolerance. Blood (ASH Annual Meeting Abstracts) 2007, I I 0: Abstract 1940.

48. Cortes J, Kantarjian HM, Baccarani M, Brummendorf TH, Liu D, Ossenkoppele G, Volkert ADG, Hewes B, Moore L, Zacharchuk C, Gambacorti C: A phase 1/2 study of SKI-606, a dual inhibitor of src and abl kinases, in adult patients with Philadelphia chromosome positive ( $\mathrm{Ph}+)$ chronic myelogenous leukemia (CML) or acute lymphocytic leukemia (ALL) relapsed, refractory or intolerant of imatinib. Blood (ASH Annual Meeting Abstracts) 2006, 108:. Abstract 168.

49. Golas JM, Arndt K, Etienne C, Lucas J, Nardin D, Gibbons J, Frost $P$, Ye F, Boschelli DH, Boschelli F: SKI-606, a 4-anilino-3-quinolinecarbonitrile dual inhibitor of Src and Abl kinases, is a potent antiproliferative agent against chronic myelogenous leukemia cells in culture and causes regression of $K 562$ xenografts in nude mice. Cancer Res 2003, 63:375-38I.

50. Puttini M, Coluccia AM, Boschelli F, Cleris L, Marchesi E, DonellaDeana A, Ahmed S, Redaelli S, Piazza R, Magistroni V, Andreoni F, Scapozza L, Formelli F, Gambacorti-Passerini C: In vitro and in vivo activity of SKI-606, a novel Src-AbI inhibitor, against imat- 
inib-resistant Bcr-Abl+ neoplastic cells. Cancer Res 2006, 66: II3I4-II322.

51. Gambacorti-Passerini C, Brummendorf T, Kantarjian H, Martinelli G, Liu D, Fisher T, Hewes B, Volkert A, Abbas R, Cortes J: Bosutinib (SKI-606) exhibits clinical activity in patients with Philadelphia chromosome positive CML or ALL who failed imatinib. J Clin Oncol (ASCO Annual Meeting Abstracts) 2007, 25(Suppl I8S):. Abstract 7006.

52. Giles FJ, Cortes J, Jones D, Bergstrom D, Kantarjian H, Freedman SJ: MK-0457, a novel kinase inhibitor, is active in patients with chronic myeloid leukemia or acute lymphocytic leukemia with the T3 I5I BCR-ABL mutation. Blood 2007, 109:500-502.

53. Giles J, Cortes J, Bergstrom DA, Xiao A, Jones D, Verstovsek S, Thomas D, Rizzieri D, Freedman SJ, Kantarjian H: MK-0457, a novel multikinase inhibitor, is active in patients with chronic myeloid leukemia (CML) and acute lymphocytic leukemia (ALL) with the T3ISI BCR-ABL resistance mutation and patients with refractory JAK2-positive myeloproliferative diseases (MPD). Haematologica (EHA Annual Meeting Abstracts) 2007, 92:347-347. Abstract 0927.

54. Paquette R, Shah NP, Sawyers CL, Martinelli G, John N, Chalukya M, Rocchetti M, Fiocchi C, Comis S, Capolongo L, Laffranchi B: PHA739358, an aurora kinase inhibitor, induces clinical responses in chronic myeloid leukemia harboring T3 I5I mutations of BCR-ABL. Blood (ASH Annual Meeting Abstracts) 2007, I I0:. Abstract 1030

55. Shakespeare WC, Wang F, Xu Q, Zhu X, Narasimham N, Metcalf CA, Wang Y, Sundaramoorthi R, Huang W, Zou D, Thomas M, Romero J, Wen D, Chen I, Cai L, Liu S, Wardwell S, Ning Y, Keats J, Snodgrass J, Russian K, Broudy M, O'Hare T, Smith C, Corbin A, Druker B, luliucci J, Dalgarno D, Sawyer TK, Clackson T: Orally active inhibitors of the imatinib resistant Bcr-Abl mutant T3I5I. Blood (ASH Annual Meeting Abstracts) 2006, 108:. Abstract 2180.

56. Zhang W: Inhibition of the drug-resistant T3I5I mutant of BCR-Abl. Eur J Cancer Supplements 2006, I 2(Suppl 4):54-54. Abstract I7I.

Publish with Bio Med Central and every scientist can read your work free of charge

"BioMed Central will be the most significant development for disseminating the results of biomedical research in our lifetime. "

Sir Paul Nurse, Cancer Research UK

Your research papers will be:

- available free of charge to the entire biomedical community

- peer reviewed and published immediately upon acceptance

- cited in PubMed and archived on PubMed Central

- yours - you keep the copyright

Submit your manuscript here:

http://www.biomedcentral.com/info/publishing_adv.asp
BioMedcentral 